\title{
Single Mathematical Parameter for Evaluation of the Microorganisms' Growth as the Objective Function in the Optimization by the DOE Techniques
}

\author{
Maciej Konopacki ${ }^{1,2, *(D)}$, Adrian Augustyniak ${ }^{1,3}{ }^{(0)}$, Bartłomiej Grygorcewicz ${ }^{2}$, \\ Barbara Dołęgowska ${ }^{2}$, Marian Kordas ${ }^{1}$ and Rafał Rakoczy ${ }^{1}$ (1) \\ 1 Department of Chemical and Process Engineering, Faculty of Chemical Technology and Engineering, \\ West Pomeranian University of Technology in Szczecin, Piastów Avenue 42, 71-065 Szczecin, Poland; \\ adrian.augustyniak@zut.edu.pl (A.A.); mkordas@zut.edu.pl (M.K.); rrakoczy@zut.edu.pl (R.R.) \\ 2 Department of Laboratory Medicine, Chair of Microbiology, Immunology and Laboratory Medicine, \\ Pomeranian Medical University in Szczecin, Powstańców Wielkopolskich Avenue 72, \\ 70-111 Szczecin, Poland; b.grygorcewicz@gmail.com (B.G.); barbara.dolegowska@pum.edu.pl (B.D.) \\ 3 Building Materials and Construction Chemistry, Technische Universität Berlin, Gustav-Meyer Allee 25, \\ 13355 Berlin, Germany \\ * Correspondence: mkonopacki@zut.edu.pl
}

Received: 16 September 2020; Accepted: 30 October 2020; Published: 31 October 2020

\begin{abstract}
The cultivation of bacteria sets a ground for studying biological processes in many scientific disciplines. The development of the bacterial population is commonly described with three factors that can be used to evaluate culture conditions. However, selecting only one of them for the optimization protocol is rather problematic and may lead to unintended errors. Therefore, we proposed a novel mathematical approach to obtain a single factor that could be used as the objective function to evaluate the whole growth dynamic and support the optimization of the biomass production process. The sigmoidal-shape curve, which is the commonly used function to plot the amount of biomass versus time, was the base for the mathematical analysis. The key process parameters, such as maximal specific growth rate and lag-phase duration were established with the use of mathematical coefficients of the model curve and combined to create the single growth parameter. Moreover, this parameter was used for the exemplary optimization of the cultivation conditions of Klebsiella pneumoniae that was cultured to be further used in the production of lytic bacteriophages. The proposed growth parameter was successfully validated and used to calculate the optimal process temperature of the selected bacterial strain. The obtained results indicated that the proposed mathematical approach could be effortlessly adapted for a precise evaluation of growth curves.
\end{abstract}

Keywords: mathematical description; bacteria cultivation; growth kinetics; optimization process; bacteriology; bacterial physiology

\section{Introduction}

The rising demand for biotechnological products as well as for the development of new bioprocesses requires continuous studies on microbial physiology and population growth $[1,2]$. In recent years, numerous studies on the optimization of cultivation conditions (e.g., medium composition, temperature, $\mathrm{pH}$ level) were conducted, which improved the mathematical description of bioprocesses [3-7]. Furthermore, the developments also regarded technological systems where bioreactors were equipped with new types of impellers, electromagnetic coils or ultrasound generators [8-10]. All these factors can affect the growth of selected microorganisms, thus the cultivation process should be optimized before every further manipulation. This implies a high number of variables that significantly increase 
the demand for experiments if one wishes to study every possibility. Design of Experiment (DOE) provides research plans that help with the choice of the experimental points for studied ranges of variables and then the creation of the response surface that describes the analysed region. For example, considering only three variables such as temperature, $\mathrm{pH}$ level and impeller speed for five different values from a selected range, a total of 125 experiments need to be conducted in order to create the response surface. Employing one of the DOE designs-central composition plan, the total number of experiments was reduced to 15 . Additionally, such a plan assumes also star points $+a$ and -a situated along each axis that allows the estimation of the response surface curvature (where star points are situated in some distance a from the centre point, $|a|>1$ ) [11-13]. The experimental area described by this design was illustrated in Figure 1.

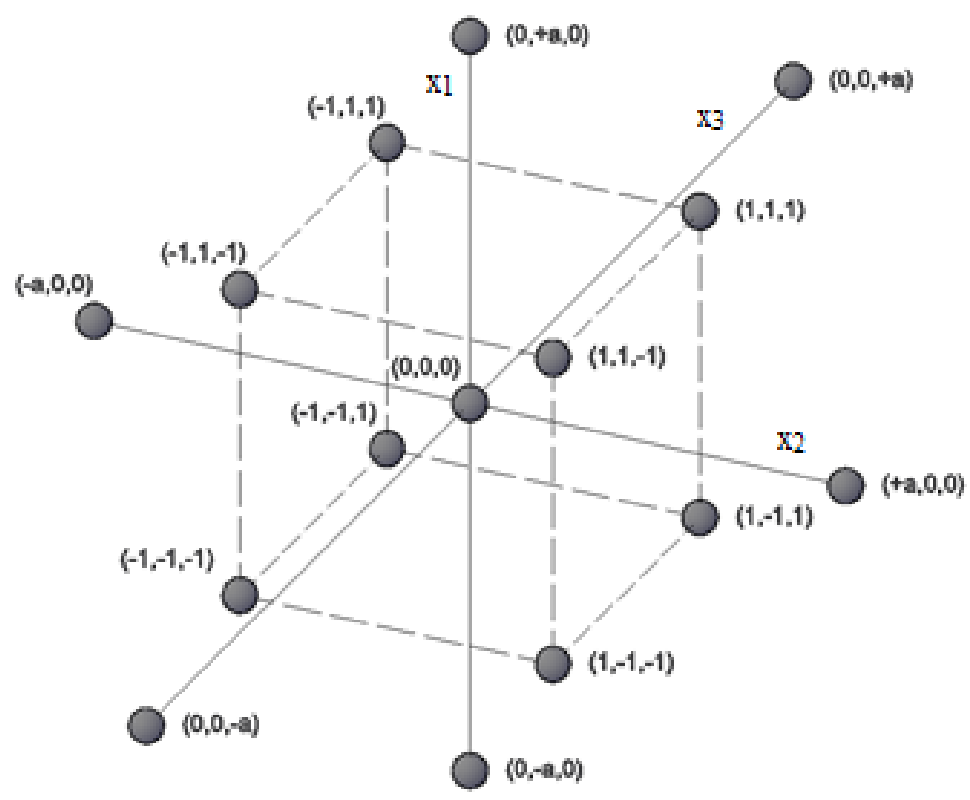

Figure 1. Experimental points given by the central composition design.

Based on the points given in Figure 1, a variable input matrix that determines the number of experiments is then created. It should be noticed, that all variables $x_{1}-x_{3}$ presented in Figure 1 and in Table 1 were standardized (all values are illustrating the distance from the middle point 0 at every variable axis). An example of a variable input matrix is presented in Table 1.

Table 1. An example of a variable input matrix.

\begin{tabular}{cccccccccccccccc}
\hline Experiment & $\mathbf{1}$ & $\mathbf{2}$ & $\mathbf{3}$ & $\mathbf{4}$ & $\mathbf{5}$ & $\mathbf{6}$ & $\mathbf{7}$ & $\mathbf{8}$ & $\mathbf{9}$ & $\mathbf{1 0}$ & $\mathbf{1 1}$ & $\mathbf{1 2}$ & $\mathbf{1 3}$ & $\mathbf{1 4}$ & $\mathbf{1 5}$ \\
\hline$x_{1}$ & 1 & -1 & 1 & -1 & 1 & -1 & 1 & -1 & $-\mathrm{a}$ & $+\mathrm{a}$ & 0 & 0 & 0 & 0 & 0 \\
$x_{2}$ & 1 & 1 & -1 & -1 & 1 & 1 & -1 & -1 & 0 & 0 & $-\mathrm{a}$ & $+\mathrm{a}$ & 0 & 0 & 0 \\
$x_{3}$ & 1 & 1 & 1 & 1 & -1 & -1 & -1 & -1 & 0 & 0 & 0 & 0 & $-\mathrm{a}$ & $+\mathrm{a}$ & 0 \\
$y$ & $y_{1}$ & $y_{2}$ & $y_{3}$ & $y_{4}$ & $y_{5}$ & $y_{6}$ & $y_{7}$ & $y_{8}$ & $y_{9}$ & $y_{10}$ & $y_{11}$ & $y_{12}$ & $y_{13}$ & $y_{14}$ & $y_{15}$ \\
\hline
\end{tabular}

$x_{1}-x_{3}$-standardized input variables (such as temperature, etc.); $y$-the objective function.

The dataset received from such design allows to create a mathematical function and to find its parameters to calculate and optimize the objective. This function can be specified as follows:

$$
y\left(x_{1}, x_{2} \ldots x_{n}\right)=p_{0}+\sum_{i=1}^{n} p_{i} x_{i}+\sum_{i=1, j=1}^{n} p_{i j} x_{i} x_{j}
$$

where: $p_{0,} p_{i}, p_{i j}$-function parameters. 
Nevertheless, in the optimization protocol, the objective function $y$ should be a single variable (making the whole procedure easier, although the multi-objective optimization approach is also possible, even though it is more complicated [14]) such as product or biomass concentration. However, growth process is described not only by the amount of biomass but also by the growth dynamic and to date there is no empirically-validated single parameter that could describe the whole bacteria growth process.

The most common way to illustrate the population growth is by drawing the growth curve that is defined as the function of the number of organisms (or logarithm of it) versus time. Optical density (OD), or colony-forming units (CFU) per millilitre are commonly used as indicators for the number of cells. The typical shape of the growth curve is sigmoid; therefore, three main phases can be marked: lag phase, logarithmic growth and stationary phase. From the perspective of the growth dynamics, each phase could be described by a single parameter. Thus, the suitable mathematical equation describing the growth curve should have at least three coefficients giving the opportunity to calculate all those parameters. The two most popular equations are the Gompertz model and simple logistic function $[15,16]$.

The optimization procedure is crucial to obtain a higher biomass production and should precede the implementation of every bioprocess. For example, many bacteria are cultivated at $37^{\circ} \mathrm{C}$ [17], because this value usually sustains the growth of human and animal pathogens such as Klebsiella pneumoniae in the diagnostic process [18]. However, this does not mean that the production of microbial biomass would be optimal at this temperature. As opposed to common bacterial models such as E. coli, to the best of our knowledge, there are no optimisation studies on the production of K. pneumoniae biomass. These bacteria may cause nosocomial infections that may lead to septicaemia and the patient's death. Isolates that are resistant to antibiotics are particularly hard to combat and therapeutic options are strictly limited. In that case, other solutions have been proposed, including the use of bacteriophages [19]. These viruses can eliminate selected bacteria and may be used to treat critically ill patients; however, they have to be grown on the target bacterium. Therefore, biomass production is essential for this application [20-23]. The biomass of these pathogens should be also produced to obtain antigens for autovaccines [24]. Furthermore, the biomass of K. pneumoniae has been used in the production of R-acetoin [25]. In order to maintain the process in the most efficient way, the cultivation parameters should be first optimized. Nevertheless, using the growth curve to find the optimal growth conditions may be hindered due to the lack of a single evaluation parameter, relating to the whole process which could be defined as the target function for the optimization process. Many researchers choose only one parameter, such as biomass concentration (without taking growth dynamic into account) or specific growth rate that is strictly associated with the logarithmic growth phase and omits the lag time and the maximal biomass concentration that could be obtained in given conditions [26,27].

Therefore, the current study aims to create and verify the mathematical description of the microorganisms' growth curve that allows the estimation of the growth parameters and that could be used as the objective function in the optimization procedure. In this case, we used K. pneumoniae as an example to describe the optimization procedure based on the growth curve observation that was influenced by the cultivation conditions changes. In the current study, we focused to show how the proposed novel parameter works, so in the experimental part we used only temperature changes to affect the bacterial growth. Nevertheless, the proposed method can be used for changes in every condition because all of them will be visible on the growth curve. This paper is also a preliminary study for further assessment of the optimal growth condition of the bacteria host cells for the bacteriophage production process. Furthermore, this research focuses on the creation of a single growth parameter that allows describing the whole process and that creates the opportunity to precisely compare the growth curves obtained in variable conditions. 


\section{Theoretical Background}

\section{Evaluation of Growth Curves}

The growth curve is often plotted as optical density (or CFU/mL) versus time. Based on the previous results [17], an example growth curve is presented in Figure 2.

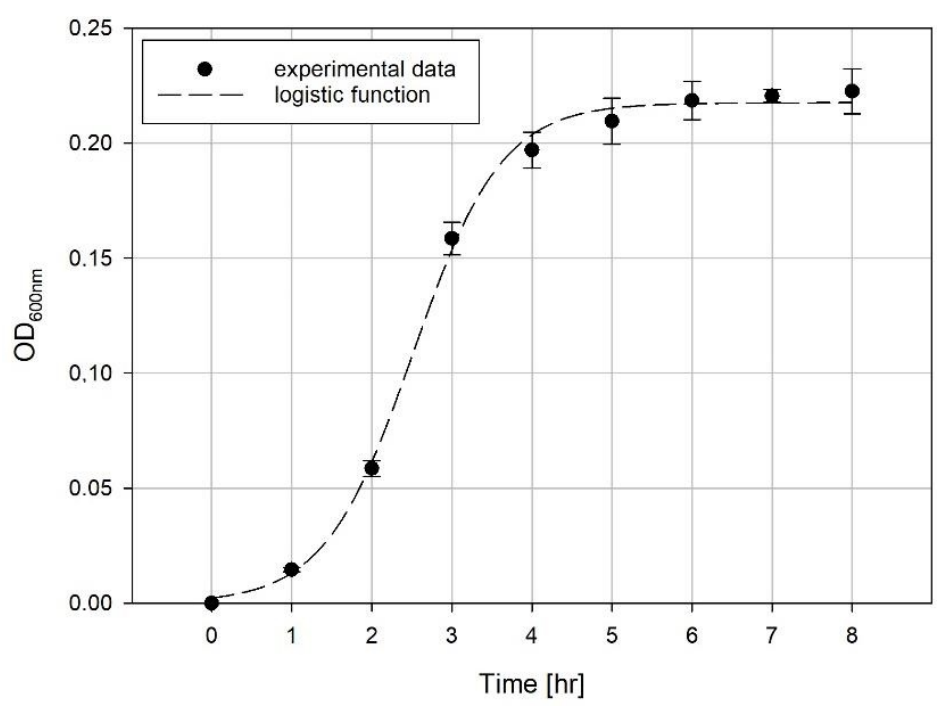

Figure 2. Example of the growth experimental data and model growth curve.

The experimental data can be described mathematically by the means of a logistic curve. In the present work, we decided to employ the following function:

$$
y(t)=\frac{a}{1+\exp (b-c t)}
$$

where: $a[-], b[-], \mathrm{c}\left[\mathrm{hr}^{-1}\right]$-mathematical function coefficients, $t$-time [hr].

These $a, b, c$ coefficients affect the model growth curve in a specific manner. The impact of each coefficient on the growth curve was described in the Supplementary Materials.

When the growth curve coefficients (given in Equation (1)) are available, a few parameters describing the population growth process can be drawn, including the maximal biomass concentration value $-A$ (asymptote), the maximal specific growth rate $-\mu_{\max }$ and the lag time $-\lambda$. Those three parameters can be specified using the function (1) coefficients as follow:

$$
\begin{gathered}
A=a[-] \\
\mu_{\max }=\frac{a c}{4}\left[\mathrm{hr}^{-1}\right] \\
\lambda=\frac{b-2}{c}[\mathrm{hr}]
\end{gathered}
$$

The detailed derivation of Equations (2)-(4) is presented in the Supplementary Materials.

The three parameters, $A, \mu_{\max }, \lambda$ can be used in the analysis of microbial growth curves [15]. However, a single parameter that describes the whole process could be preferably used, if properly described. For example, a weighted arithmetic mean of these parameters could theoretically serve as such parameter, although the prediction of weight values for each of the three values would be unclear and subjective. For that reason, we decided to propose a different approach based on the analysis of the growth potential by the area under the curve [28], where the mathematical description would result in a novel single parameter that takes into consideration all those three parameters. 
Assuming the ideal conditions, the best growth kinetics would be infinitely fast with no lag time, resulting in a maximal possible concentration level that is limited by the asymptote $A_{\max }$, which can be noted as:

$$
\mu_{\max } \rightarrow \infty, \lambda \rightarrow 0, A=A_{\max }
$$

For such an assumption, the ideal growth curve would be rectangular with a height of $A_{\max }$ and a length of $t$. In that case, the ideal growth potential could be described as:

$$
F=A_{\max } t
$$

In a realistic situation, the growth curve area is mostly limited by the specific growth line $y_{t}(t)$ and the asymptote A. Both, ideal and realistic, situations are presented in Figure 3.

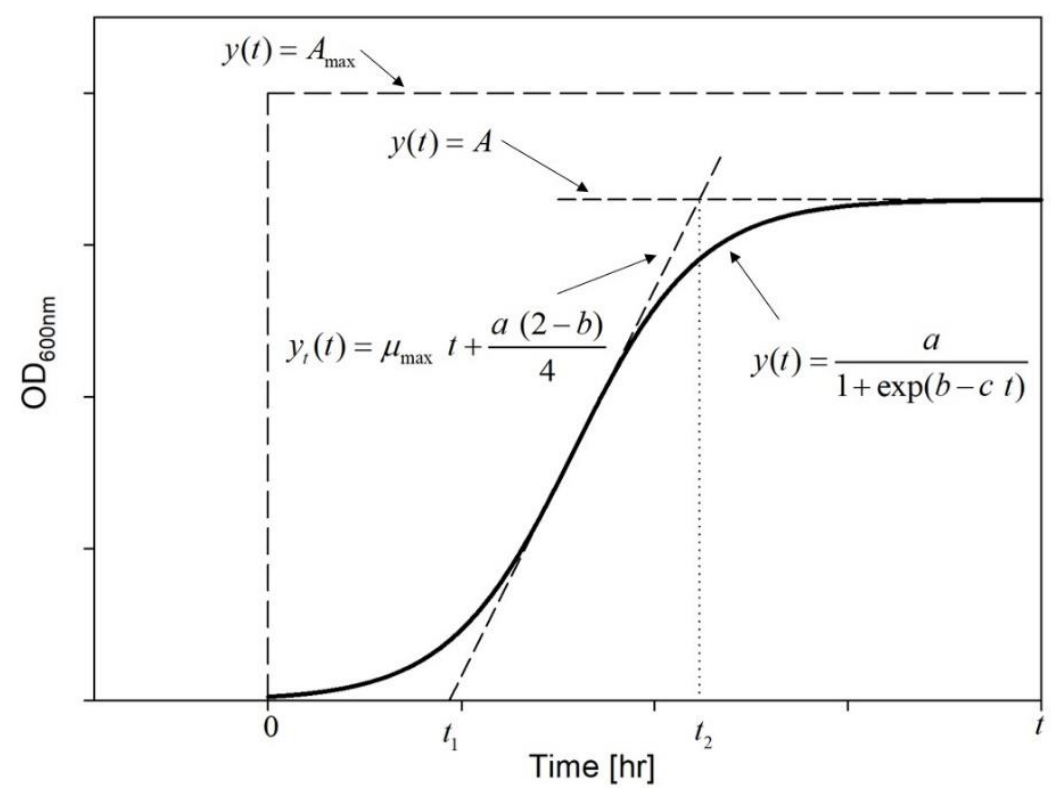

Figure 3. Schematic representation of the area under the growth curve together with the mathematical function describing boundary lines.

It should be noticed that the area under the realistic growth curve resembles the trapezoid form. The length of both bases is specified by the time $(t)$ and two specific points $\left(t_{1}, t_{2}\right)$ given by the interception of the tangent line: first with the $x$-axis and second with the asymptote $A$ (see Figure 3 ). Thus:

$$
\begin{gathered}
t_{1}=\lambda \rightarrow t_{1}=\frac{b-2}{c} \\
\mathrm{y}_{t}\left(t_{2}\right)=\mathrm{A} \rightarrow \mathrm{t}_{2}=\frac{b+2}{c}
\end{gathered}
$$

The area under the curve for realistic conditions can be defined as:

$$
f=A \frac{\left(t-t_{1}\right)+\left(t-t_{2}\right)}{2}
$$

The combined form of Equations (7) and (8), is drawn as follows:

$$
f=a t-\frac{a b}{c}
$$

The single parameter that we have decided to use in the evaluation of growth curves is the ratio between the area under curves for realistic and ideal conditions:

$$
\varphi=\frac{f}{F}
$$


After having substituted Equations (6) and (9) to Equation (10), the single growth parameter is received:

$$
\varphi=\left(\frac{a}{A_{\max }}\right)\left(1-\frac{b}{c t}\right)
$$

Specifying the maximal growth ratio to be described by $n_{A}=\frac{a}{A_{\max }}$, the final form of the growth parameter is defined as:

$$
\varphi=n_{A}\left(1-\frac{b}{c t}\right)[-]
$$

This parameter could be used prior to comparing different growth curves obtained in the laboratory experiments, especially for the optimization process. It should be emphasized that the calculated parameter can be utilized only if the experiment time $(t)$ is equal for every curve and sufficient large to reach the plateau phase. This allows us to avoid calculation errors. Moreover, the $A_{\max }$ value should be established experimentally at the highest obtained number or assumed from the literature, for a given range of operating conditions. When the maximal growth is the same for all datasets, i.e., $A=A_{\max }$, then the equation describing the growth parameter $\varphi$ can be simplified to the following formula:

$$
\varphi=1-\frac{b}{c t}[-]
$$

Additionally, we performed a visualization of the growth parameter changes by each input parameter $(a, b, c)$ variations by plotting its estimated value in the specified region. The results are presented in the Supplementary Materials.

\section{Materials and Methods}

Klebsiella pneumoniae (ATCC ${ }^{\circledR}$ BAA-1706 ${ }^{\mathrm{TM}}$ ) was used in laboratory experiments. Bacteria were kept frozen in Trypticase Soy Broth medium (TSB) with 10\% (v/v) glycerol.

Refrozen cultures were streaked to Trypticase Soy Agar (TSA) medium and incubated at $37^{\circ} \mathrm{C}$ for $24 \mathrm{~h}$. Afterwards, a colony was transferred to $30 \mathrm{~mL}$ of fresh TSB medium and incubated overnight (14-16 h) at $37^{\circ} \mathrm{C}$. In the next step, $300 \mathrm{~mL}$ of TSB at the test temperature was inoculated in ratio 1:100 and evenly dispensed to the $15 \mathrm{~mL}$ Falcon tubes (10 mL of inoculum to each tube). At this time, 8 samples $(100 \mu \mathrm{L}$ each) were taken from the inoculum and medium and their optical density (OD, at $\lambda=600 \mathrm{~nm}$ ) was measured on BioTek Synergy H1 (Winooski, VT, USA) spectrophotometer. The experiments were continued for $10 \mathrm{~h}$ to achieve the plateau phase. One tube was taken every hour and 8 samples (100 $\mu \mathrm{L}$ each) were subjected to OD measurements. Experiments were led at six selected temperatures, including $25^{\circ} \mathrm{C}, 27.3{ }^{\circ} \mathrm{C}, 33^{\circ} \mathrm{C}, 37^{\circ} \mathrm{C}, 38.7^{\circ} \mathrm{C}$ and $41^{\circ} \mathrm{C}$. Furthermore, the metabolic activity of cells was controlled in MTT and resazurin assays, as described elsewhere [29,30]. In order to perform all tests for each sample, the time selected for the incubation of biochemical tests was 20 min. In the case of MTT, cells were disrupted with DMSO $(99.99 \%, 100 \mu \mathrm{L}$ per sample) and further incubated for $15 \mathrm{~min}$.

\section{Results and Discussion}

The experimental data of K. pneumoniae cultures in the tested range of temperatures are presented in Figure 4. The cultures were led until they all reached the plateau phase. As a result of the slower growth at $25^{\circ} \mathrm{C}$, the curves were prolonged up to the 10 th hour.

The obtained dataset was described by the logistic function Equation (1) using the Statistica 13 (Statsoft, Kraków, Poland) software and the least square error method. In result, the function coefficients were obtained with a very good model adjustment. All obtained values are presented in Table 2.

Maximal growth, maximum specific growth rate and lag time were calculated with the use of Equations (2)-(4), respectively. The results are presented in Figure 5. 


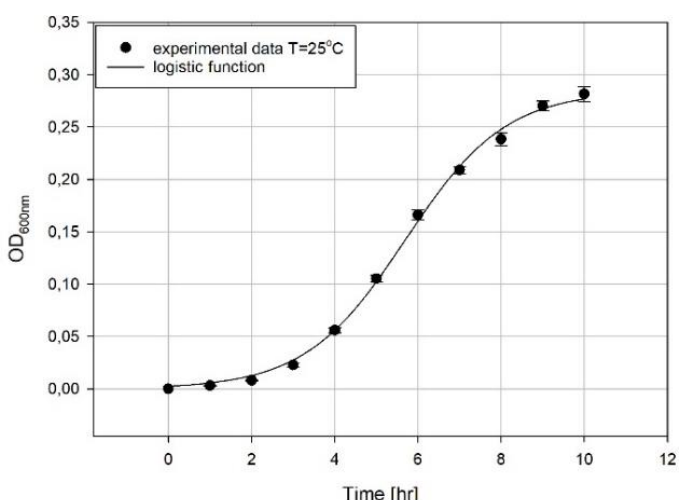

(a)

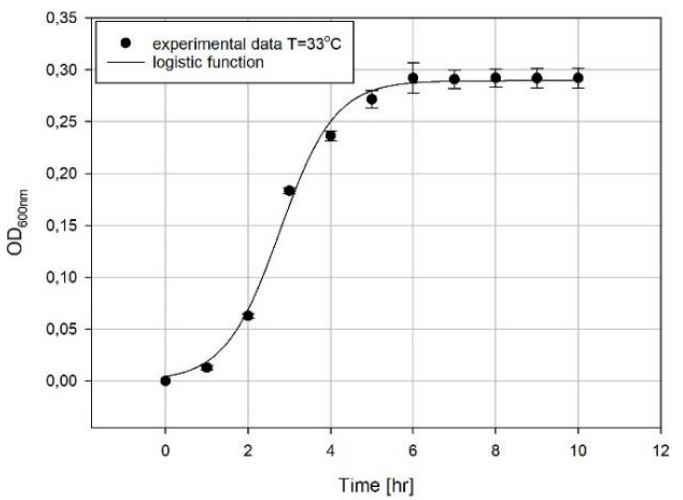

(c)

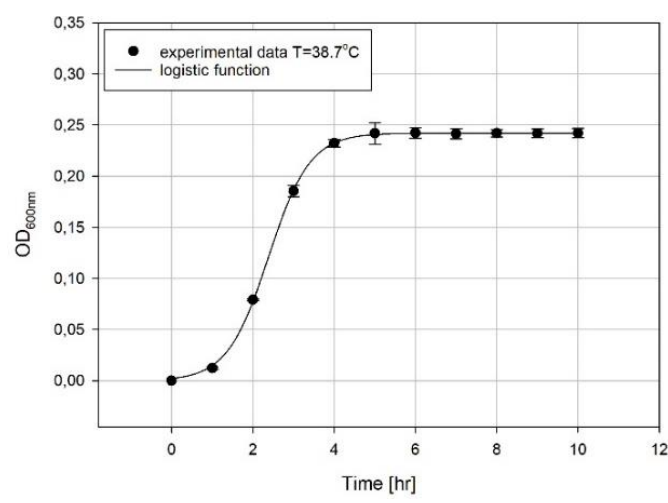

(e)

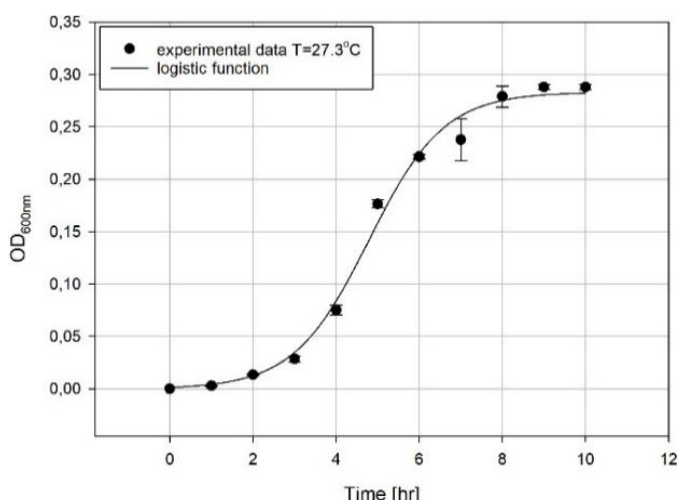

(b)

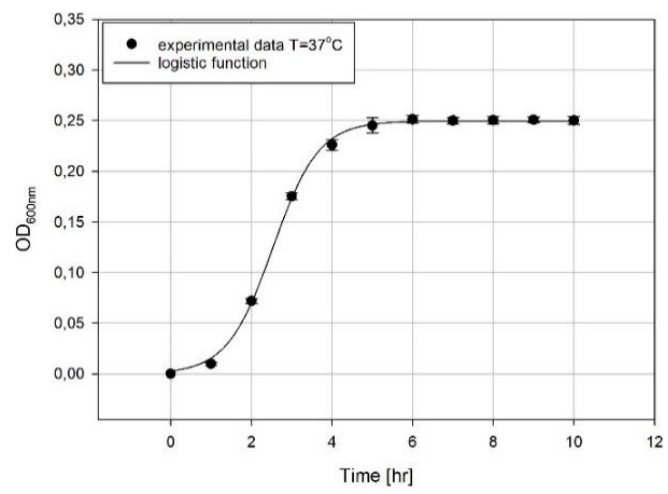

(d)

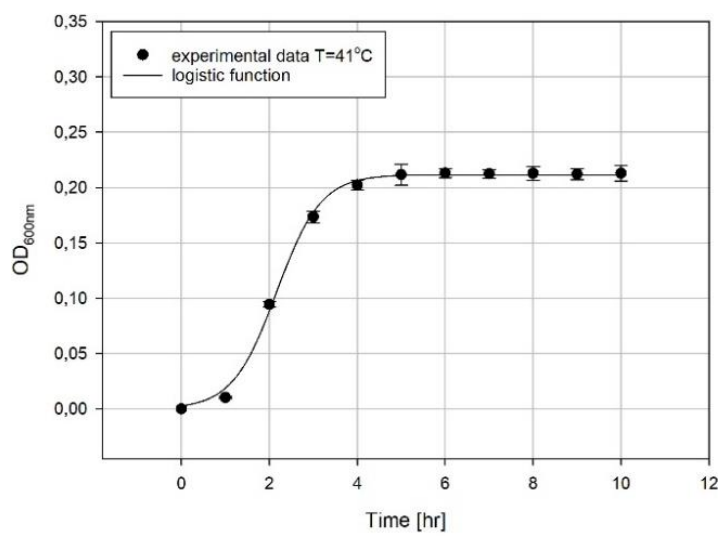

(f)

Figure 4. The growth of $\mathrm{K}$. pneumoniae in various temperatures: (a) $\mathrm{T}=25^{\circ} \mathrm{C},(\mathbf{b}) \mathrm{T}=27.3^{\circ} \mathrm{C}$, (c) $\mathrm{T}=33^{\circ} \mathrm{C}$, (d) $\mathrm{T}=37^{\circ} \mathrm{C},(\mathbf{e}) \mathrm{T}=38.7^{\circ} \mathrm{C}$, (f) $\mathrm{T}=41^{\circ} \mathrm{C}$.

Table 2. Growth curve model function coefficients in selected temperatures.

\begin{tabular}{|c|c|c|c|c|}
\hline \multirow{2}{*}{ Temperature $\left[{ }^{\circ} \mathrm{C}\right]$} & \multicolumn{3}{|c|}{ Function Coefficients } & \multirow{2}{*}{$R^{2}$} \\
\hline & $a$ & $b$ & $c$ & \\
\hline 25 & 0.2846 & 4.7225 & 0.8289 & 0.9981 \\
\hline 27.3 & 0.2831 & 5.2786 & 1.1033 & 0.9929 \\
\hline 33 & 0.2895 & 4.1777 & 1.5073 & 0.9959 \\
\hline 37 & 0.2495 & 1.7655 & 1.7655 & 0.9991 \\
\hline 38.7 & 0.2421 & 4.6926 & 1.9688 & 0.9998 \\
\hline 41 & 0.2116 & 4.3208 & 1.9952 & 0.9978 \\
\hline
\end{tabular}




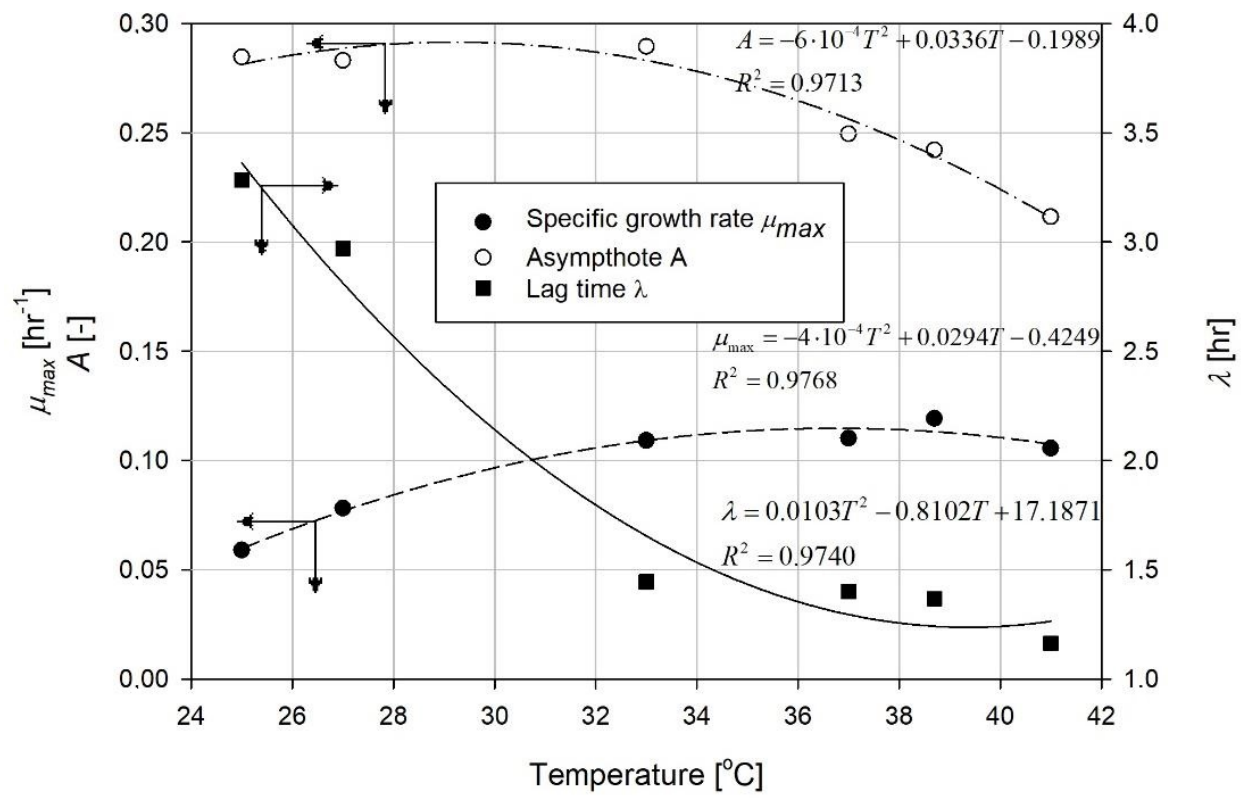

Figure 5. Changes of growth parameters with the process temperature. The approximations were conducted by the method of least squares.

The maximum specific growth rate (Figure 5, filled circles) increased with the temperature up to $33^{\circ} \mathrm{C}$. Afterwards, it changed slightly, fluctuating around $0.11 \mathrm{hr}^{-1}$. The lag time (Figure 5, filled squares) strongly depended on the temperature, especially in the lower region $\left(25-33^{\circ} \mathrm{C}\right)$. Generally, the rise in temperature was followed by a drop in the lag time. Above $33^{\circ} \mathrm{C}$, this effect was slower but also measurable. The maximum growth concentration specified by asymptote was also affected by temperature (Figure 5, empty circles). The final OD reached in the cultures was bigger for the lower range of temperatures $\left(25-33^{\circ} \mathrm{C}\right)$. The further rise in the temperature resulted in a strong decrease in the value of the asymptote.

Calculating the optimal temperature with the use of 3 parameters is rather complicated thus, the growth parameter $\varphi$ was calculated according to Equation (13). These results are presented in Figure 6.

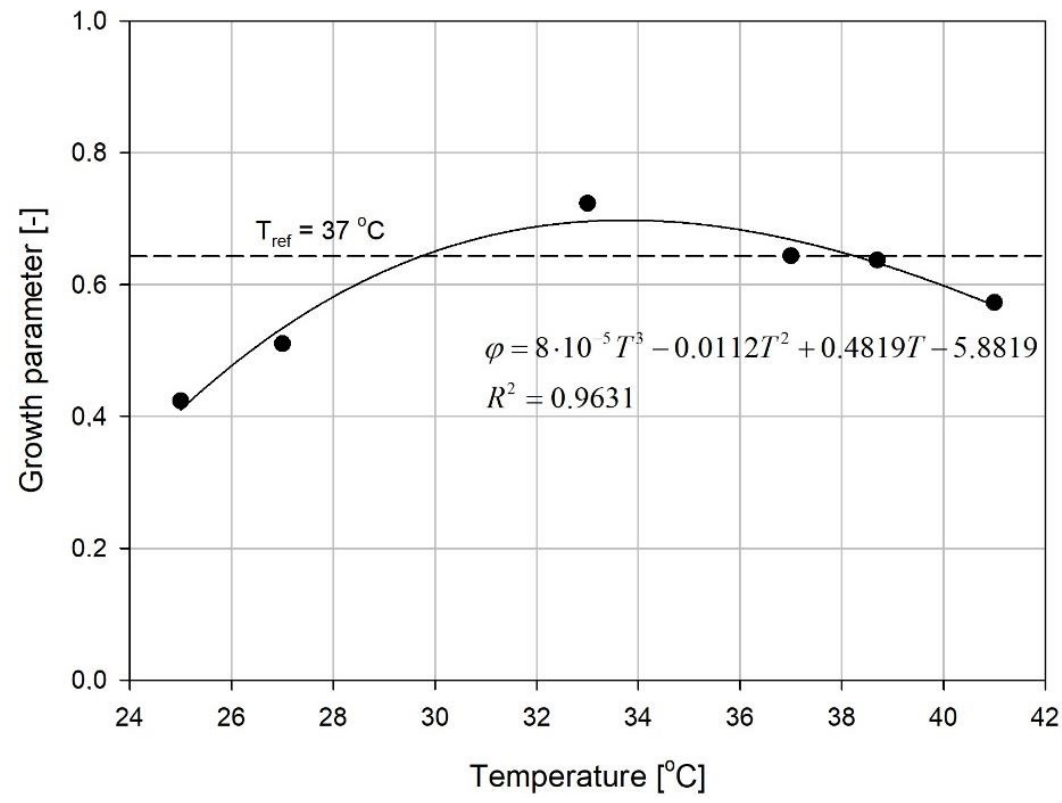

Figure 6. Changes in the growth parameter $\varphi$ of the process temperature. The approximations were conducted by means of the method of least squares. 
The calculated values of growth parameters (Figure 6) presented the region of optimal temperature around $33-34{ }^{\circ} \mathrm{C}$. The population growth was improved by $12 \%$ in comparison to the result obtained at $37^{\circ} \mathrm{C}$. Thus, $37^{\circ} \mathrm{C}$ has not been the optimal temperature for the cultivation of bacteria, even though it is commonly used in the research on K. pneumoniae and other representatives of this genus [2,25]. Therefore, the effective biomass production could be performed at lower temperatures that would reduce the energy (heat) consumption, thus the cost of the process [1]. Our analysis supports the notion that it is crucial to experimentally find the optimal conditions before heading to the production process. A well-fitted curve to growth parameter versus temperature plot would give in that case the precise optimum for the process temperature (in the studied case its $33.8^{\circ} \mathrm{C}$ ). As shown above, the experimental results confirmed that the obtained $\varphi$ value was higher at this range of the temperature than at the commonly used $37^{\circ} \mathrm{C}$ [31]. Interestingly, it has been suggested in the literature that the best results in biochemical testing of clinical strains of $\mathrm{K}$. pneumoniae are obtained at $33-34{ }^{\circ} \mathrm{C}$ [18].

\section{Conclusions}

Several parameters, such as maximum specific growth rate or the lag time can describe the growth of bacterial population. Nevertheless, we have shown that the proposed single parameter could be a convenient tool to evaluate the growth during the optimization process. The fitting of the logistic function to the growth curve was relatively simple and produced the adjusted coefficients with very high accuracy. The known values of function coefficients allow the rapid evaluation of the curve with the use of the growth parameter that makes this approach very straightforward and reliable. The experimental data have validated the model showing that the optimal temperature for the cultivation of $\mathrm{K}$. pneumoniae is $33.8^{\circ} \mathrm{C}$. The reasoning behind the proposed single parameter has the potential to be further used also with other bacteria than K. pneumoniae. The proposed approach can be applied in the optimization of the biomass production for biotechnological processes, including the production of phage-based solutions, or lysates for autovaccines.

Supplementary Materials: The following are available online at http://www.mdpi.com/2076-2607/8/11/1706/s1, Figure S1. Impact of model growth curve coefficients: (a) a = var, b, c = const ( $b=3, c=0.6)$; (b) b = var, $a, c$ $=$ const $(\mathrm{a}=0.1, \mathrm{c}=0.6) ;(\mathrm{c}) \mathrm{c}=$ var, $\mathrm{a}, \mathrm{b}=$ const $(\mathrm{a}=0.1, \mathrm{~b}=3)$, Figure S2. The influence of the model function coefficients on the growth parameter $(\varphi)$ in the constant process time $(16 \mathrm{~h})$ : (a) a-value $(b=3, c=0.6)$, (b) b-value $(a=0.1, c=0.6),(c) c-v a l u e(a=0.1, b=3)$, Figure S3. The influence of $b$ and c coefficients on the growth parameter in the constant process time $(16 \mathrm{~h})$ and with $\mathrm{A}=\mathrm{A}_{\max }$.

Author Contributions: Conceptualization, M.K. (Maciej Konopacki); Data curation, M.K. (Maciej Konopacki); Funding acquisition, R.R.; Investigation, M.K. (Maciej Konopacki), A.A., B.G. and M.K. (Marian Kordas); Methodology, M.K. (Maciej Konopacki); Project administration, R.R.; Supervision, B.D. and R.R.; Visualization, M.K. (Maciej Konopacki) and M.K. (Marian Kordas); Writing—original draft, M.K. (Maciej Konopacki), A.A., B.G. and R.R. All authors have read and agreed to the published version of the manuscript.

Funding: This study was funded by the National Science Centre, Poland (OPUS 16, Project No. UMO-2018/31/B/ST8/03170, granted to Rafał Rakoczy).

Acknowledgments: Adrian Augustyniak was supported by the German Research Foundation (DFG) as part of the Research Training Group on Urban Water Interfaces (GRK 2032).

Conflicts of Interest: The authors declare no conflict of interest.

\section{References}

1. Cardoso, V.M.; Campani, G.; Santos, M.P.; Silva, G.G.; Pires, M.C.; Gonçalves, V.M.; Giordano, R.D.C.; Sargo, C.R.; Horta, A.C.; Zangirolami, T.C. Cost Analysis Based on Bioreactor Cultivation Conditions: Production of a Soluble Recombinant Protein Using Escherichia coli BL21(DE3). Biotechnol. Rep. 2020, 26, e00441. [CrossRef]

2. Cha, J.W.; Jang, S.H.; Kim, Y.J.; Chang, Y.K.; Jeong, K.J. Engineering of Klebsiella Oxytoca for Production of 2,3-Butanediol Using Mixed Sugars Derived from Lignocellulosic Hydrolysates. GCB Bioenergy 2020, 12, 275-286. [CrossRef] 
3. Tashiro, T.; Yoshimura, F. A Neo-Logistic Model for the Growth of Bacteria. Phys. A Stat. Mech. Appl. 2019, 525, 199-215. [CrossRef]

4. Pereira, S.; Otero, A. Haematococcus Pluvialis Bioprocess Optimization: Effect of Light Quality, Temperature and Irradiance on Growth, Pigment Content and Photosynthetic Response. Algal Res. 2020, 51, 102027. [CrossRef]

5. Derakhshandeh, M.; Un, U.T. Optimization of Microalgae Scenedesmus SP. Growth Rate Using a Central Composite Design Statistical Approach. Biomass Bioenergy 2019, 122, 211-220. [CrossRef]

6. Gelain, L.; Van Der Wielen, L.; Van Gulik, W.M.; Pradella, J.G.D.C.; Da Costa, A.C. Mathematical Modelling for the Optimization of Cellulase Production Using Glycerol for Cell Growth and Cellulose as the Inducer Substrate. Chem. Eng. Sci. 2020, 116048. [CrossRef]

7. Medina-Cabrera, E.V.; Rühmann, B.; Schmid, J.; Sieber, V. Optimization of Growth and EPS Production in Two Porphyridum Strains. Bioresour. Technol. Rep. 2020, 11, 100486. [CrossRef]

8. Lechowska, J.; Kordas, M.; Konopacki, M.; Fijałkowski, K.; Drozd, R.; Rakoczy, R. Hydrodynamic Studies in Magnetically Assisted External-Loop Airlift Reactor. Chem. Eng. J. 2019, 362, 298-309. [CrossRef]

9. Rakoczy, R.; Konopacki, M.; Lechowska, J.; Bubnowska, M.; Hürter, A.; Kordas, M.; Fijałkowski, K. Gas to Liquid Mass Transfer in Mixing System with Application of Rotating Magnetic Field. Chem. Eng. Process. Process Intensif. 2018, 130, 11-18. [CrossRef]

10. Konopacka, A.; Rakoczy, R.; Konopacki, M. The Effect of Rotating Magnetic Field on Bioethanol Production by Yeast Strain Modified by Ferrimagnetic Nanoparticles. J. Magn. Magn. Mater. 2019, 473, 176-183. [CrossRef]

11. Yang, J.; Ma, C.; Tao, J.; Li, J.; Du, K.; Wei, Z.; Chen, C.; Wang, Z.; Zhao, C.; Ma, M. Optimization of Polyvinylamine-Modified Nanocellulose for Chlorpyrifos Adsorption by Central Composite Design. Carbohydr. Polym. 2020, 245, 116542. [CrossRef] [PubMed]

12. Leili, M.; Khorram, N.S.; Godini, K.; Azarian, G.; Moussavi, R.; Peykhoshian, A. Application of Central Composite Design (CCD) for Optimization of Cephalexin Antibiotic Removal Using Electro-Oxidation Process. J. Mol. Liq. 2020, 313, 113556. [CrossRef]

13. Kenawy, I.M.; Eldefrawy, M.M.; Eltabey, R.M.; Zaki, E. Melamine Grafted Chitosan-Montmorillonite Nanocomposite for Ferric Ions Adsorption: Central Composite Design Optimization Study. J. Clean. Prod. 2019, 241, 118189. [CrossRef]

14. Chang, K.-H. Multiobjective Optimization and Advanced Topics. In Design Theory and Methods Using $C A D / C A E$; Elsevier BV: Amsterdam, The Netherlands, 2015; pp. 325-406.

15. Zwietering, M.H.; Jongenburger, I.; Rombouts, F.M.; Riet, K.V.T. Modeling of the Bacterial Growth Curve. Appl. Environ. Microbiol. 1990, 56, 1875-1881. [CrossRef] [PubMed]

16. Zwietering, M.H.; De Koos, J.T.; Hasenack, B.E.; De Witt, J.C.; Riet, K.V. Modeling of Bacterial Growth as a Function of Temperature. Appl. Environ. Microbiol. 1991, 57, 1094-1101. [CrossRef]

17. Konopacki, M.; Rakoczy, R. The Analysis of Rotating Magnetic Field as a Trigger of Gram-Positive and Gram-Negative Bacteria Growth. Biochem. Eng. J. 2019, 141, 259-267. [CrossRef]

18. Grimont, P.A.D.; Grimont, F. Klebsiella. In Bergey's Manual of Systematics of Archaea and Bacteria; Wiley: Hoboken, NJ, USA, 2015; pp. 1-26. [CrossRef]

19. Mattila, S.; Ruotsalainen, P.; Jalasvuori, M. On-Demand Isolation of Bacteriophages against Drug-Resistant Bacteria for Personalized Phage Therapy. Front. Microbiol. 2015, 6, 1271. [CrossRef]

20. Grygorcewicz, B.; Grudziński, M.; Wasak, A.; Augustyniak, A.; Pietruszka, A.; Nawrotek, P. BacteriophageMediated Reduction of Salmonella Enteritidis in Swine Slurry. Appl. Soil Ecol. 2017, 119, 179-182. [CrossRef]

21. Augustyniak, A.; Grygorcewicz, B.; Nawrotek, P. Isolation of Multidrug Resistant Coliforms and Their Bacteriophages from Swine Slurry. Turk. J. Vet. Anim. Sci. 2018, 42, 319-325. [CrossRef]

22. Danis-Wlodarczyk, K.; Vandenheuvel, D.; Bin Jang, H.; Briers, Y.; Olszak, T.; Arabski, M.; Wasik, S.; Drabik, M.; Higgins, G.; Tyrrell, J.; et al. A Proposed Integrated Approach for the Preclinical Evaluation of Phage Therapy in Pseudomonas Infections. Sci. Rep. 2016, 6, 28115. [CrossRef]

23. Konopacki, M.; Grygorcewicz, B.; Dołegowska, B.; Kordas, M.; Rakoczy, R. PhageScore: A Simple Method for Comparative Evaluation of Bacteriophages Lytic Activity. Biochem. Eng. J. 2020, 161, 107652. [CrossRef]

24. Zagólski, O.; Stręk, P.; Kasprowicz, A.; Białecka, A. Effectiveness of Polyvalent Bacterial Lysate and Autovaccines Against Upper Respiratory Tract Bacterial Colonization by Potential Pathogens: A Randomized Study. Med. Sci. Monit. 2015, 21, 2997-3002. [CrossRef] 
25. Wei, D.; Gu, J.; Zhang, Z.; Wang, C.; Kim, C.H.; Jiang, B.; Shi, J.; Hao, J. Production of Chemicals by Klebsiella Pneumoniae Using Bamboo Hydrolysate as Feedstock. J. Vis. Exp. 2017, 1-7. [CrossRef]

26. Tsuchiya, K.; Cao, Y.-Y.; Kurokawa, M.; Ashino, K.; Yomo, T.; Ying, B.-W. A Decay Effect of the Growth Rate Associated with Genome Reduction in Escherichia coli. BMC Microbiol. 2018, 18, 101. [CrossRef] [PubMed]

27. Peleg, M.; Corradini, M.G. Microbial Growth Curves: What the Models Tell Us and What They Cannot. Crit. Rev. Food Sci. Nutr. 2011, 51, 917-945. [CrossRef] [PubMed]

28. Todor, H.; Dulmage, K.; Gillum, N.; Bain, J.R.; Muehlbauer, M.J.; Schmid, A.K. A Transcription Factor Links Growth Rate and Metabolism in the Hypersaline Adapted Archaeon Halobacterium Salinarum. Mol. Microbiol. 2014, 93, 1172-1182. [CrossRef] [PubMed]

29. Sikora, P.; Augustyniak, A.; Cendrowski, K.; Nawrotek, P.; Mijowska, E. Antimicrobial Activity of $\mathrm{Al}_{2} \mathrm{O}_{3}$, $\mathrm{CuO}, \mathrm{Fe}_{3} \mathrm{O}_{4}$, and $\mathrm{ZnO}$ Nanoparticles in Scope of Their Further Application in Cement-Based Building Materials. Nanomaterials 2018, 8, 212. [CrossRef]

30. Provost, J.; Wallert, M. MTT Proliferation Assay Protocol. Available online: http://web.mnstate.edu/provost/ MTTProliferationAssayProtocol2012.pdf (accessed on 15 September 2020).

31. Cuzon, G.; Naas, T.; Truong, H.; Villegas, M.-V.; Wisell, K.T.; Carmeli, Y.; Gales, A.C.; Navon-Venezia, S.; Quinn, J.P.; Nordmann, P. Worldwide Diversity of Klebsiella Pneumoniae That Produce $\beta$-lactamase blaKPC-2Gene. Emerg. Infect. Dis. 2010, 16, 1349-1356. [CrossRef]

Publisher's Note: MDPI stays neutral with regard to jurisdictional claims in published maps and institutional affiliations. 